NATIONAL LABORATORY

MANAGED BY UT-BATTELLE

FOR THE DEPARTMENT OF ENERGY

\title{
The Impact of Carbon Control on Electricity and Gasoline Expenditures of Low-Income Households
}

\section{April 2008}

Prepared by

Joel Eisenberg

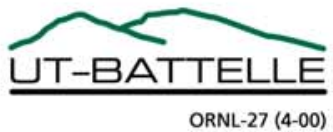




\section{DOCUMENT AVAILABILITY}

Reports produced after January 1, 1996, are generally available free via the U.S. Department of Energy (DOE) Information Bridge.

Web site http://www.osti.gov/bridge

Reports produced before January 1, 1996, may be purchased by members of the public from the following source.

National Technical Information Service

5285 Port Royal Road

Springfield, VA 22161

Telephone 703-605-6000 (1-800-553-6847)

TDD 703-487-4639

Fax 703-605-6900

E-mail info@ntis.gov

Web site http://www.ntis.gov/support/ordernowabout.htm

Reports are available to DOE employees, DOE contractors, Energy Technology Data Exchange (ETDE) representatives, and International Nuclear Information System (INIS) representatives from the following source.

Office of Scientific and Technical Information

P.O. Box 62

Oak Ridge, TN 37831

Telephone 865-576-8401

Fax 865-576-5728

E-mail reports@osti.gov

Web site http://www.osti.gov/contact.html

This report was prepared as an account of work sponsored by an agency of the United States Government. Neither the United States Government nor any agency thereof, nor any of their employees, makes any warranty, express or implied, or assumes any legal liability or responsibility for the accuracy, completeness, or usefulness of any information, apparatus, product, or process disclosed, or represents that its use would not infringe privately owned rights. Reference herein to any specific commercial product, process, or service by trade name, trademark, manufacturer, or otherwise, does not necessarily constitute or imply its endorsement, recommendation, or favoring by the United States Government or any agency thereof. The views and opinions of authors expressed herein do not necessarily state or reflect those of the United States Government or any agency thereof. 


\title{
THE IMPACT OF CARBON CONTROL ON ELECTRICITY AND GASOLINE EXPENDITURES OF LOW-INCOME HOUSEHOLDS
}

\author{
Joel Eisenberg
}

Date Published: April 2008

\section{Prepared by}

OAK RIDGE NATIONAL LABORATORY

Oak Ridge, Tennessee 37831-6283

managed by

UT-BATTELLE, LLC

for the

U.S. DEPARTMENT OF ENERGY

under contract DE-AC05-00OR22725 



\section{CONTENTS}

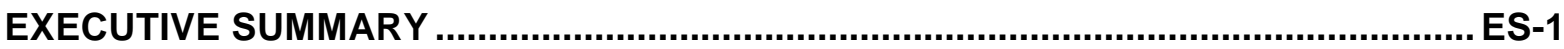

INTRODUCTION

CAP-AND-TRADE

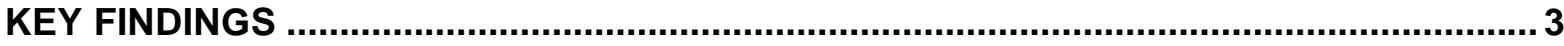

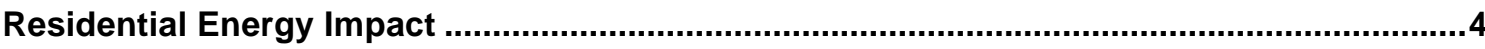

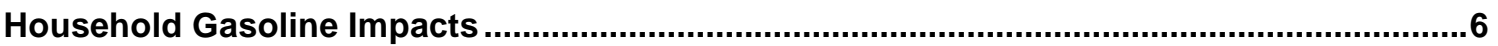

CONCLUSIONS

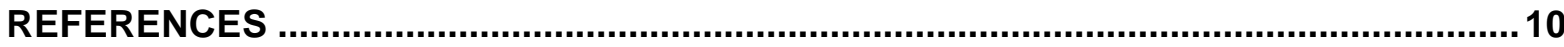

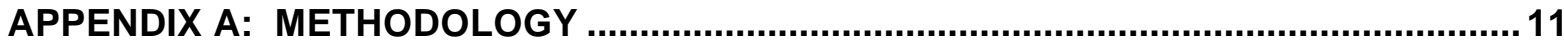

APPENDIX B: MAP OF CENSUS DIVISIONS AND REGIONS ….................................13 


\section{EXECUTIVE SUMMARY}

In July of 2007 The Department of Energy's (DOE's) Energy Information Administration (EIA) released its impact analysis of "The Climate Stewardship And Innovation Act of 2007," known as S.280. This legislation, cosponsored by Senators Joseph Lieberman and John McCain, was designed to significantly cut U.S. greenhouse gas emissions over time through a "cap-and-trade" system, briefly described below, that would gradually but extensively reduce such emissions over many decades. S.280 is one of several proposals that have emerged in recent years to come to grips with the nation's role in causing human-induced global climate change. ${ }^{1}$

EIA produced an analysis of this proposal using the National Energy Modeling System (NEMS) to generate price projections for electricity and gasoline under the proposed cap-and-trade system. Oak Ridge National Laboratory integrated those price projections into a data base derived from the EIA Residential Energy Consumption Survey (RECS) for 2001 and the EIA public use files from the National Household Transportation Survey (NHTS) for 2001 to develop a preliminary assessment of impact of these types of policies on low-income consumers. ORNL will analyze the impacts of other specific proposals as EIA makes its projections for them available.

The EIA price projections for electricity and gasoline under the S.280 climate change proposal, integrated with RECS and NHTS for 2001, help identify the potential effects on household electric bills and gasoline expenditures, which represent S.280's two largest direct impacts on low-income household budgets in the proposed legislation. The analysis may prove useful in understanding the needs and remedies for the distributive impacts of such policies and how these may vary based on patterns of location, housing and vehicle stock, and energy usage.

\section{CAP-AND-TRADE}

Many U.S. policy makers now believe that to slow and eventually stop the impact of greenhouse gases on the world's climate the United States must slow and then greatly reduce its own use of carbon-based fuels. Among the proposed strategies to achieve this objective is the use of a "capand-trade" system that would set a limit or cap on greenhouse gas emissions, measured in tons of $\mathrm{CO}_{2}$ equivalent emitted each year, and gradually reduce that limit over time. Producers or users of fossil fuels would be required to hold permits to allow them to emit $\mathrm{CO}_{2}$, each permit entitling the holder to emit a ton of $\mathrm{CO}_{2}$ equivalent. The number of these permits, sometimes called "allowances," would be reduced over time, consistent with the cap.

The impact of such a system would begin small but would become significant over time, depending on many factors such as the price of alternative energy sources, the introduction of new cost-effective sustainable energy technologies, the rate of economic growth, and the potential to offset carbon emissions through energy efficiency or carbon sequestration. Under S.280 the carbon emissions cap would be set at the 2004 level for the period 2012-2019, at the 1990 level for the period 2020 to 2029 , at 78 percent of the 1990 level for the period 2030 to 2049 , and at 40 percent of that level thereafter.

\footnotetext{
${ }^{1}$ These include the recommendations of the National Commission on Energy Policy incorporated into draft legislation by Senator Bingaman; S. 309 introduced by Senator Sanders; S. 317 by Senator Feinstein; S. 485 by Senator Kerry; S.2191 by Senators Lieberman and Warner; H.R. 620 by Representative Olver; and H.R. 1590 by Representative Waxman.
} 


\section{KEY FINDINGS}

All impacts are estimated in 2005 dollars.

- A carbon cap-and-trade program similar to S.280 focused on the electricity industry and petroleum refiners will have a gradually deepening impact on low-income consumers. In real terms, the electricity bills of low-income consumers will increase by approximately 9 percent by 2020 and by 20 percent by 2030 relative to what they would have been without the program, i.e., business as usual. The average low-income electricity bill will rise by $\$ 167$, from $\$ 833$ to $\$ 1000$, during that time frame.

- The impact on gasoline consumers will be a cost increase of approximately 8 percent by 2020 and 16 percent by 2030 relative to business as usual. These increases would average $\$ 152$ by 2020 and $\$ 323$ by 2030 .

\section{Residential Energy Impact}

- Low-income households spend a disproportionate share of their income on residential energy, and the impact of a cap-and-trade policy that increases the per-unit price of electricity will therefore be regressive.

- The impacts will not be evenly distributed geographically. Those regions more heavily dependent on coal for electric generation will experience greater price increases according to EIA, and their low-income households will see a more severe escalation in the price of electricity.

- Low-income households in the Midwest and South will be more severely affected than those in the Northeast or West. The average annual low-income electricity bill will rise by $\$ 85$ in the Northeast and $\$ 97$ in the West by 2030. On the other hand, in the Midwest the average increase will be $\$ 233$ and in the South it will be $\$ 220$. (Please see Appendix B for complete map of the states by Census Region and Division.)

- In addition to geography, other factors illuminate the regional disparities in the impact of cap-and-trade among low-income consumers. These may include such elements as a housing type, number and age of appliances, and electric energy usage habits.

- High-impact households, defined as the top 25 percent of low-income households in terms of the increase in their annual electricity bills, will experience increases in excess of $\$ 235$. The average increase for this high-impact group will be $\$ 342$ by 2030 , compared to the average increase of $\$ 166$ for all low-income households. See Figure ES-1 for a graphical depiction of the distribution of impacts.

- Many of the high-impact households, 43 percent, use electricity to heat their homes. Those heating with electricity in the East South Central Division are projected to experience an average increase of $\$ 339$ per annum, and many will be hit by increases in excess of $\$ 400$. In contrast, low-income households in the Pacific Division heating with natural gas would find their energy costs increasing by an average of $\$ 52$ per year. Regional concentrations of low-income households and high-impact, low-income households are shown in Figure ES-2. 


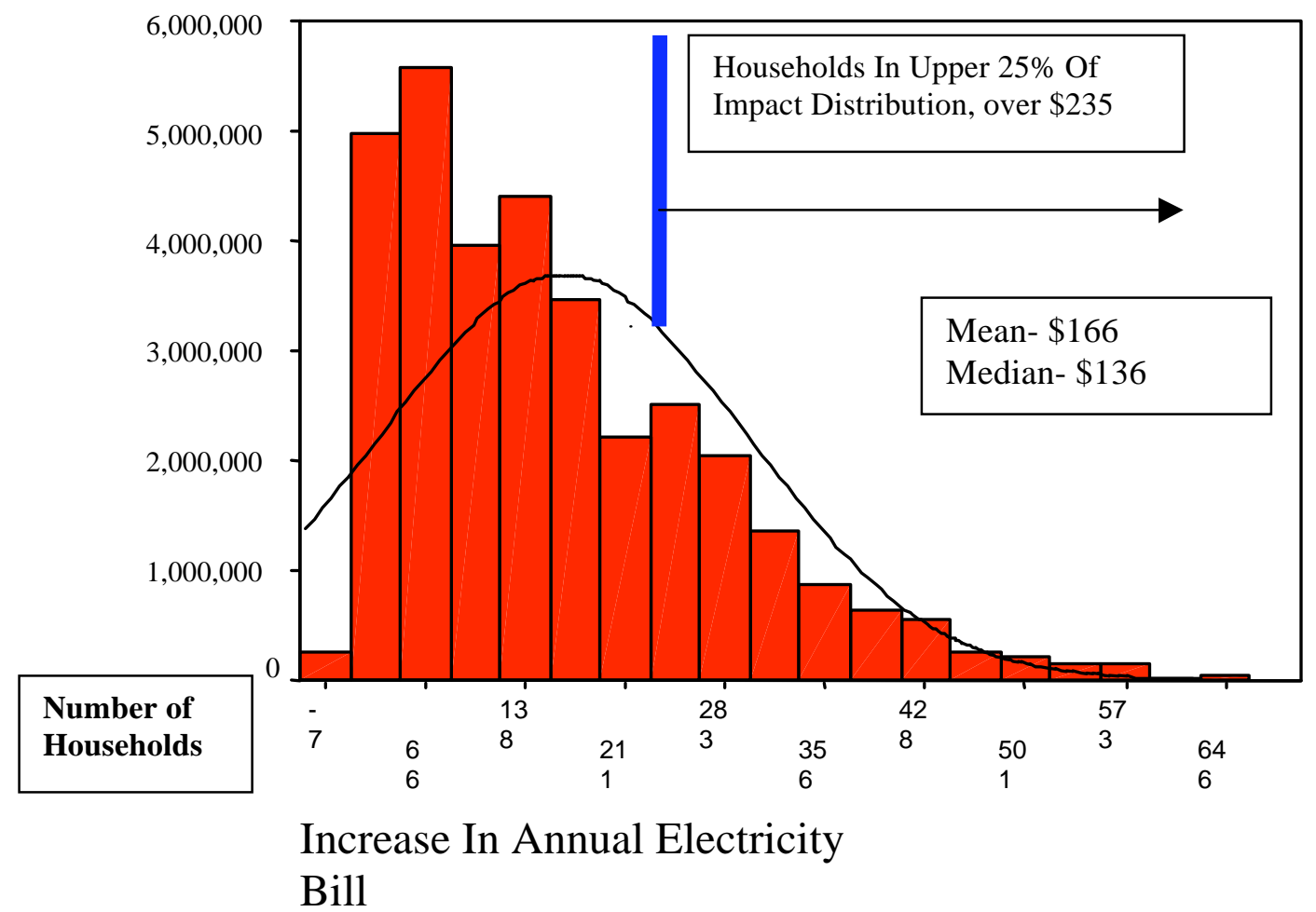

Figure ES-1. Distribution of low-income electric bill increases as a result of cap-and-trade in 2030 (2005 dollars).

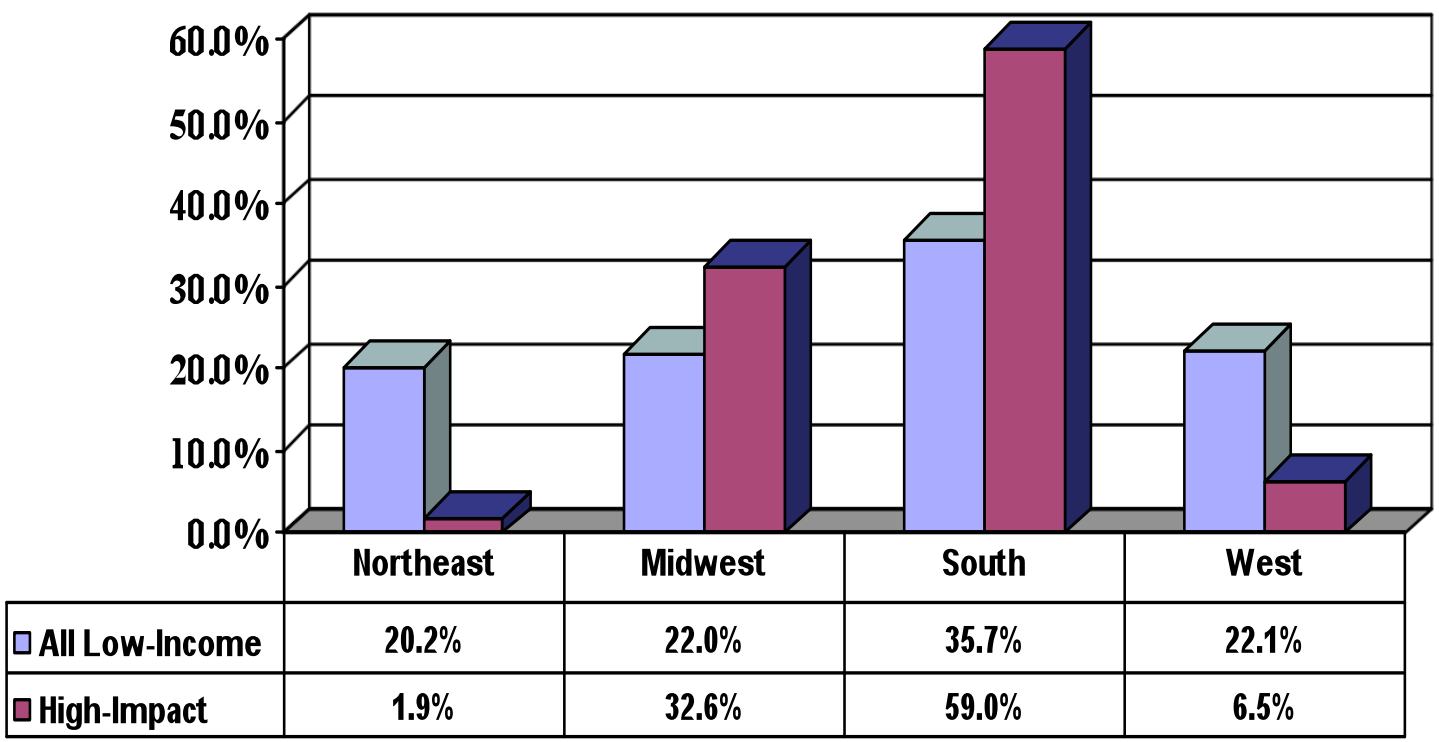

Figure ES-2. Location of all low-income households and high-impact, low-income households, percentage by region. (Sources: Residential Energy Consumption Survey, 2001, and ORNL analysis of $\mathbf{S . 2 8 0}$ using EIA price projections.) 
- High-impact households have higher electricity consumption, higher total energy consumption, and higher energy usage per square foot of living space when compared to the averages for all low-income households. Average kWh electricity consumption for high-impact households is 16,179 per annum compared to 8,971 for all low-income households.

- Eighty-one percent of the high-impact households live in either mobile homes or singlefamily detached homes. For the low-income population in general only 54 percent live in these two types of homes.

\section{Gasoline Cost Impacts}

- In the business-as-usual case low-income household expenditures for households with vehicles will average $\$ 1829$ per year in 2020 and $\$ 2052$ per year in 2030. This will increase by $\$ 153$ in 2020 and $\$ 323$ in 2030 under the cap-and-trade scenario.

- Low-income households with personal vehicles had average consumption of 902 gallons per year in 2001 compared to 1231 gallons for non-low-income households. Their average expenditures are lower than those of non-low-income households but not in proportion to their lower income. Their personal travel burden, measured as expenditures divided by income, is therefore substantially higher than those of higher income households. A policy that increases the per-gallon price of gasoline will therefore be regressive.

- The impact of cap-and-trade policies on low-income household vehicle expenditures will vary significantly within that population depending on a variety of characteristics including but not limited to vehicle types and numbers owned, geographic location, distances traveled, and ultimately gallons consumed on an annual basis. While the average impact is estimated at $\$ 323$ per year, those in the highest quartile of impact will see an average increase of $\$ 750$ per year. The variation and broad distribution of impacts can be seen in Figure ES-3 below.

- A unique characteristic of the variation in impacts is the substantial number of lowincome households, approximately 19 percent, that are estimated to have no vehicle at all. (These do not even appear in Figure ES-3.) This compares to approximately 3 percent of the non-low-income households. A disproportionate number of these low-income households with no vehicles are located in the Mid-Atlantic Census Division, but the majority, 73 percent, are found spread across other parts of the country.

- An examination of the survey data reveals that, as one might expect, low-income households are much less likely to own late-model cars. Approximately 47 percent of their vehicles were at least ten years old at the time of the survey.

- Another clear distinction among low-income households is the difference between households in rural areas and those in non-rural areas. Those in rural areas would experience an average increase of $\$ 424$ per year in 2030 whereas those in non-rural areas will see an average increase of $\$ 291$. 


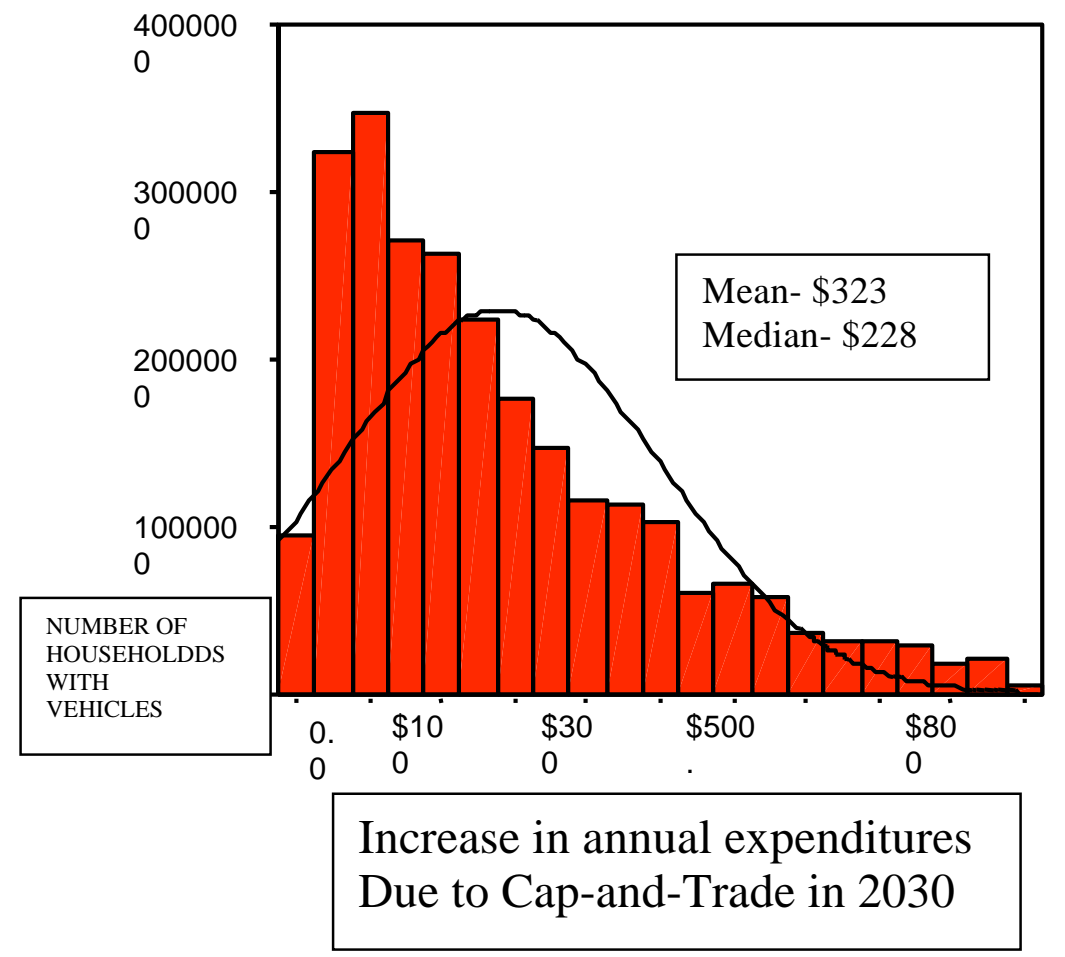

Figure ES-3. Impact of cap-and-trade on low-income gasoline expenditures for households with vehicles in 2030 (2005 dollars).

\section{CONCLUSIONS}

- This preliminary analysis of one cap-and-trade carbon policy indicates that there will be a substantial impact of such a policy on low-income energy expenditures. This impact will begin at a relatively small level in the years immediately ahead and increase over the following decades as the level of carbon dioxide emitted in the U.S. is increasingly constrained.

- The breadth of the impact of a substantial cap-and-trade policy, comparable to the reductions proposed in S.280 and similar proposals, will vary substantially with the program design. The proposal evaluated in this analysis imposes its carbon emissions requirements at the level of large emitters such as power plants and on refineries, and the impact on energy bills for low-income households is therefore largely concentrated in the electricity and gasoline consumption sectors. Other proposals, such as the LiebermanWarner bill, S.2191, seek to impose the allowance requirements on more fuels and at different levels in the supply chain. This would be more likely to have a high impact on those using natural gas or fuel oil as their primary heat source. In this regard the general design matters. 
- Residential and transportation energy expenditures are only part of the regressive impact of a cap-and-trade policy on low-income households because higher energy costs to producers of other essential goods and services are likely to be passed to their customers. Direct energy expenses will, nonetheless, be a significant proportion of the impact of a large-scale carbon pricing policy on low-income households, as the figures above demonstrate.

- These impacts on direct energy expenditures are likely to vary substantially by region, fuel type for electric generation, housing type and condition, vehicle age and condition, and numerous other factors. General income redistribution mechanisms such as withholding tax adjustments or the Earned Income Tax Credit may be a major vehicle for helping to deal with the general consumption impacts of the policy and basic energy usage, but may not be well suited to deal with the energy-specific variations explored in this report. This is because those mechanisms are not designed to take these highly varied energy-related benefit requirements into account, nor to deliver energy efficiency services.

- Appropriately funded and designed low-income energy assistance has a significant role to play in dealing with these impact disparities among and within the different regions of the country, because the benefits can be varied to target high-impact households.

- The residential energy usage profile of high-impact, low-income households, living disproportionately in detached single family homes and consuming more electricity and more energy in general than other low-income households, indicates that they stand to benefit substantially from energy efficiency investments.

- The gradual introduction of the cap-and-trade carbon restrictions and accompanying price impacts creates a window of opportunity to employ energy efficiency to cushion the future impacts. During the next decade residential building envelope retrofits and appliance replacement, as well as improved auto fleet efficiency targeted at those in the high-impact segment of the low-income population, can help reduce the need for future energy assistance while also reducing the carbon footprint of low-income communities.

- Low-income electricity and gasoline consumption, expenditures, and cap-and-trade impacts exhibit substantial variation among households. A significant portion of this variation is a function of the characteristics of the housing stock and vehicle fleet. The durability of the housing stock is such that most of the homes now in that stock will still be in use in 2030, whereas most of the vehicle stock will not. This implies that retrofit policies as well as new housing efficiency standards will play a major role in reducing the impact of cap-and-trade on low-income electricity expenses, whereas new vehicle efficiency standards will have the greatest impact on gasoline expenditures.

- Further analysis of carbon reduction policies with projections of future housing, appliance, and vehicle fleet profiles, as well as various projections of the size, demographics, and economic well-being of the low-income population will help better assess remedial requirements for these policies as well as better inform targeting for energy assistance and energy efficiency efforts. 


\section{INTRODUCTION}

In July of 2007 the U.S. Department of Energy's (DOE's) Energy Information Administration (EIA) released its impact analysis of "The Climate Stewardship And Innovation Act of 2007," known as S.280. This legislation, cosponsored by Senators Joseph Lieberman and John McCain, was designed to significantly cut U.S. greenhouse gas emissions over time through a "cap-andtrade" system that would gradually but extensively reduce such emissions over many decades using a mechanism that is briefly described below. This legislation is one of several proposals that have emerged in recent years to come to grips with this nation's role in causing humaninduced global climate change. ${ }^{2}$

An analysis of this proposal produced by EIA used the National Energy Modeling System (NEMS) to generate price projections for electricity and gasoline under the proposed cap-andtrade system. Oak Ridge National Laboratory integrated those price projections into a data base derived from the EIA Residential Energy Consumption Survey (RECS) for 2001 and the EIA public use files from the National Household Transportation Survey (NHTS) for 2001 to develop a preliminary assessment of the impact of these types of policies on low-income consumers.

ORNL has developed these projections in order to give policy makers a sense of the potential magnitude of the impact of carbon control on low-income consumers' direct residential energy and gasoline expenditures over time, as well as a sense of how those impacts may vary from region to region and among groups and households within the low-income population. For purposes of this analysis, low-income households are defined as those at or below the greater of 150 percent of the federal Poverty Level or 60 percent of state median income, the federal maximum eligibility standard for the Low Income Home Energy Assistance Program (LIHEAP) and the DOE Weatherization Assistance Program. This population was estimated at approximately 33.8 million households in 2001 in RECS.

Previous analyses of greenhouse gas reduction policies by the Congressional Budget Office and others have demonstrated that the cost of reducing carbon emissions will tend to be regressive, affecting lower-income consumers more severely on a percentage-of-income basis than it would upper- or middle-income households (CBO 2003). A recent study for the Brookings Institution estimated that the potential impact of a $\$ 15$-per-ton carbon tax on those having income in the lowest 10 percent of all households is a 3.4 percent drop in income, and for the next lowest 10 percent, a drop of 3.1 percent. This compares to approximately 1.5 percent for the middle-income groups and 0.8 percent of income for those having incomes in the highest 10 percent (Metcalf 2007). An analysis by the Center on Budget and Policy Priorities estimates that households in the poorest fifth of all U.S. households would experience an increase of $\$ 750-\$ 950$ for all goods and services as the result of a cap-and-trade program that drops carbon emissions 15 percent below projected business-as-usual levels (CBPP 2007).

The EIA price projections for electricity and gasoline under the S.280 climate change proposal, integrated with the RECS and NHTS for 2001, help identify the potential effects on household electric bills and gasoline expenditures, which represent the two largest direct impacts on lowincome household budgets in the proposed legislation. The analysis may prove useful in understanding the needs and remedies for the distributive impacts of such policies and how varied

\footnotetext{
${ }^{2}$ These include the recommendations of the National Commission on Energy Policy incorporated into draft legislation by Senator Bingaman; S. 309 introduced by Senator Sanders; S. 317 by Senator Feinstein; S.485 by Senator Kerry; S.2191 by Senators Lieberman and Warner; H.R. 620 by Representative Olver; and H.R. 1590 by Representative Waxman.
} 
these may be based on patterns of location, housing and vehicle stock, and energy usage. The estimates do not attempt to differentiate among alternative legislative proposals, nor do they provide an estimate of aggregate impacts on the low-income population across time. Since the price impacts are estimated decades ahead, for 2020 and 2030, the aggregate estimates would require projections of population growth and poverty rates as well as housing, appliance, income, and energy profiles far into the future and are beyond the scope of the present work. This analysis estimates what the household impact of the policy might be for consumers with current fuel use and consumption profiles.

\section{CAP-AND-TRADE}

The United States is a major driver of the world economy and also a major emitter of greenhouse gases such as carbon dioxide $\left(\mathrm{CO}_{2}\right)$ through its extensive use of fossil fuels such as coal, petroleum, and natural gas. Many U.S. policy makers now believe that to slow and eventually stop the impact of these gases on the world's climate the United States must slow and then greatly reduce its own use of these carbon-based fuels. Among the proposed strategies for achieving this objective is the use of a "cap-and-trade" system that would set a limit or cap on greenhouse gas emissions, measured in tons of $\mathrm{CO}_{2}$ equivalent emitted each year, and gradually reduce that limit over time. Producers or users of fossil fuels would be required to hold permits to allow them to emit $\mathrm{CO}^{2}$, each permit entitling the holder to emit a ton of $\mathrm{CO}^{2}$ equivalent. The number of these permits, sometimes called "allowances," would be reduced over time, consistent with the cap. Permit holders would be free to buy and sell permits in an open market. As the cap decreases the number of permits would also decrease, thereby increasing their price and that of carbon-based energy that they enable.

The impact of such a system would begin small but would become significant over time, depending on many factors such as the price of alternative energy sources, the introduction of new cost-effective sustainable energy technologies, the rate of economic growth, and the potential to offset carbon emissions through energy efficiency or carbon sequestration. Under S.280 the carbon emissions cap would be set at the 2004 level for the period 2012-2019, at the 1990 level for the period 2020 to 2029, at 78 percent of the 1990 level for the period 2030 to 2049, and at 40 percent of that level thereafter. EIA has estimated that the cost of an allowance will rise to $\$ 22.20$ by 2020 and $\$ 47.90$ by 2030 in constant 2005 dollars based on reference case economic assumptions (EIA 2007).

This study does not explicitly estimate the impact on low-income households of a carbon tax, which is one of the major policy alternatives to a cap-and-trade program. Though there can be profound differences between a cap-and-trade program and a carbon tax in terms of administration, impact on energy markets, and impact on emissions, both kinds of vehicles will raise the cost of residential energy produced from carbon-based fuels. For purposes of understanding the direction of low-income energy expenditures and the regional, housing, and fuel-use variations that would occur with a carbon tax that is comparably effective in reducing emissions to S.280, the reader can assume that the impact on low-income electric expenditures will also be roughly comparable to those presented below for the cap-and-trade program.

There are many alternative design choices for a cap-and-trade greenhouse gas reduction program that can have a significant impact on the scope, scale, and impact of the program. A full description of these is well beyond the reach of this study, but a mention of several will illustrate the potential complexities and significance of the choices made. 
1. How high a cost are we willing to pay? A cap-and-trade program, like a carbon tax, will use price as the major mechanism to reduce carbon consumption and increase the economic feasibility of using non-carbon-based fuels that might not otherwise be considered cost-effective. The higher energy prices caused by the cap would also create incentives for research, development, and deployment of new energy technologies, though there remains substantial disagreement regarding the price of efficiency and renewable energy substitutes, and therefore the cost of the cap. There is general scientific agreement that $\mathrm{CO}_{2}$ already in the atmosphere will remain there for generations and that a major cut back, at least on the scale of S.280, will be required to slow and eventually stop its further accumulation. How high a price will today's consumers be willing to pay for a benefit that may not occur for several generations down the road?

2. Who will need a permit? Some proposals call for energy producers and importers to hold the permits in order to sell their fossil fuels. Others would place the requirement lower down the energy consumption chain at the emissions source itself, such as at power generation and industrial plants. The higher up the chain the greater the administrative simplicity of the system, while the lower down towards the end consumer, the closer to those whose choices will be affected by the higher prices. Choosing to place the burden on major industrial users, power generators, and refiners enables the program to minimize the impact on small consumers such as those who heat with natural gas, but also can concentrate the impact on certain energy sources such as electricity and gasoline.

3. How will permits be allocated? The basic choices here are whether permits will be allocated to current users of fossil fuels, sold to those same users, allocated to others for public purposes or some mixture of these approaches. Over time the impact in all cases is to raise the cost to those who use carbon-intensive energy but the initial impact on these users is much reduced if they are allocated permits. This would tend to reduce the immediate impact on electricity prices where coal is used for generation and power systems have not been deregulated. On the other hand, if permits are sold this raises revenue that can be recirculated to consumers, used to develop and deploy alternative energy and energy efficiency resources, or used to reduce the impact of price hikes on low-income households. Most proposals for cap-and-trade have recognized the regressive nature of the policy and the need to return funding to low- and middle-income consumers although there is no consensus on the mechanisms that should be used for doing so.

\section{KEY FINDINGS}

All impacts are estimated in 2005 dollars.

- A carbon cap-and-trade program similar to S.280 focused on the electric industry and petroleum refiners will have a gradually deepening impact on low-income consumers. In real terms, the electricity bills of low-income consumers will increase by approximately 9 percent by 2020 and by 20 percent by 2030 relative to what they would have been without the program, i.e., business as usual. The average electricity bill for the lowincome consumer will rise by $\$ 167$, from $\$ 833$ to $\$ 1000$, during that time frame. 
- The impact on gasoline consumers will be an increase of approximately 8 percent by 2020 and 16 percent by 2030 relative to business as usual. These increases would average $\$ 152$ by 2020 and $\$ 323$ by 2030 .

\section{Residential Energy Impact}

- There will be some variation in the residential energy impact based on primary heating fuel, as shown in Table 1. Electric bills vary among households using different heating fuels, and the impact of cap-and-trade in 2030 will therefore range from an average of $\$ 143$ for households heating with natural gas to $\$ 260$ for households heating with propane. Households heating with propane tend to have relatively high electricity usage and are more heavily concentrated in areas where EIA projects electricity prices to rise more severely.

Table 1. Mean low-income residential electricity expenditures per household with and without a cap-and-trade in 2030 by primary household heating fuel (\$2005)

\begin{tabular}{|l|c|c|c|c|c|}
\hline \multicolumn{1}{|c|}{ Year } & Natural Gas & Propane & Fuel Oil & Electricity & All \\
\hline Baseline & $\$ 705$ & $\$ 1050$ & $\$ 885$ & $\$ 1018$ & $\$ 833$ \\
\hline Cap-and- trade & $\$ 848$ & $\$ 1310$ & $\$ 1028$ & $\$ 1219$ & $\$ 1000$ \\
\hline $\begin{array}{l}\text { Increases due to } \\
\text { cap-and- trade }\end{array}$ & $\$ 143$ & $\$ 260$ & $\$ 143$ & $\$ 201$ & $\$ 167$ \\
\hline
\end{tabular}

- The impacts will not be evenly distributed geographically. Those regions more heavily dependent on coal for electric generation will experience greater price increases according to EIA, and their low-income households will see a more severe escalation in the price of electricity.

- Low-income households in the Midwest and South will be much more severely affected than those in the Northeast or West. The average annual low-income electricity bill will rise by $\$ 85$ in the Northeast and $\$ 97$ in the West by 2030 . On the other hand, in the Midwest the average increase will be \$233 and in the South it will be \$220.

- On a sub-regional basis the disparity in average annual impacts is even more severe. For example, on the Pacific Coast and in New England the increase will be, respectively, \$54 and $\$ 69$ per annum in 2030. In that year in the West North Central Census Division, the average increase will be $\$ 284$, a jump of 33 percent. Similarly, in the East South Central Division, the increase will be 25 percent, or approximately $\$ 274$. (Please see Appendix B for complete map of the states by Census Region and Division.) 


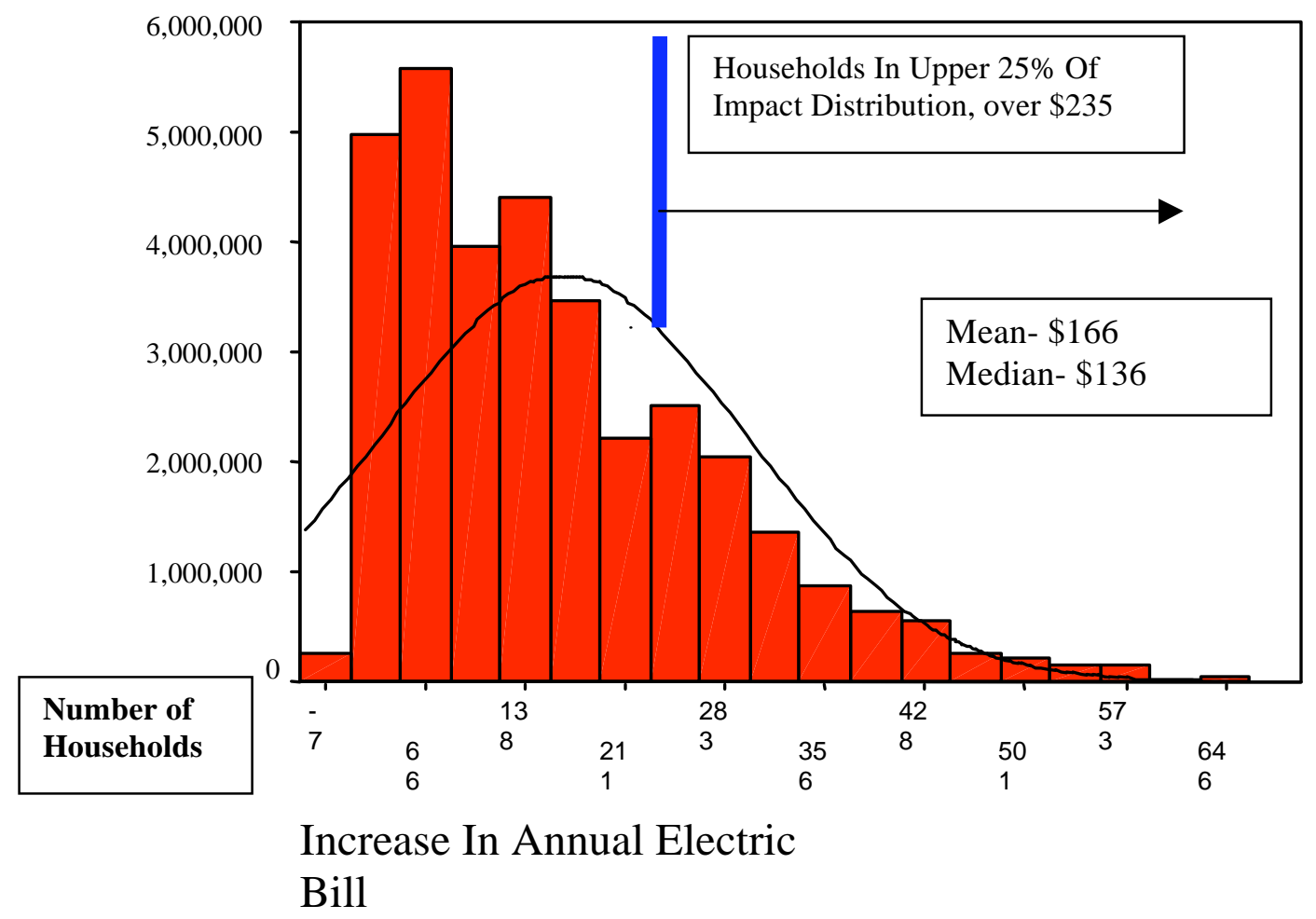

Figure 1. Distribution of low-income electric bill increases as a result of cap-and-trade in 2030 (2005 dollars).

- In addition to geography, other factors illuminate the regional disparities in the impact of cap-and-trade among low-income consumers. These may include such elements as a housing type, number and age of appliances, and electric energy usage habits.

- High-impact households, defined as the top 25 percent of low-income households in terms of the increase in their annual electricity bills, will experience increases in excess of $\$ 235$ by 2030 , compared to the average of $\$ 166$ for all low-income households. See Figure 1 for a graphical depiction of the distribution of impacts.

- Of these high-impact households, a disproportionate number will come from the West South Central Census Division and the East North Central Division, in addition to the divisions previously highlighted.

- Many of the high-impact households, 43 percent, use electricity to heat their homes. Those heating with electricity in the East South Central Division are projected to experience an average increase of $\$ 339$ per annum, and many will be hit by increases in excess of \$400. In contrast, low-income households in the Pacific Division heating with natural gas would find their energy costs increasing by an average of $\$ 52$ per year. Regional concentrations of low-income households and high-impact, low-income households are shown in Figure 2. 


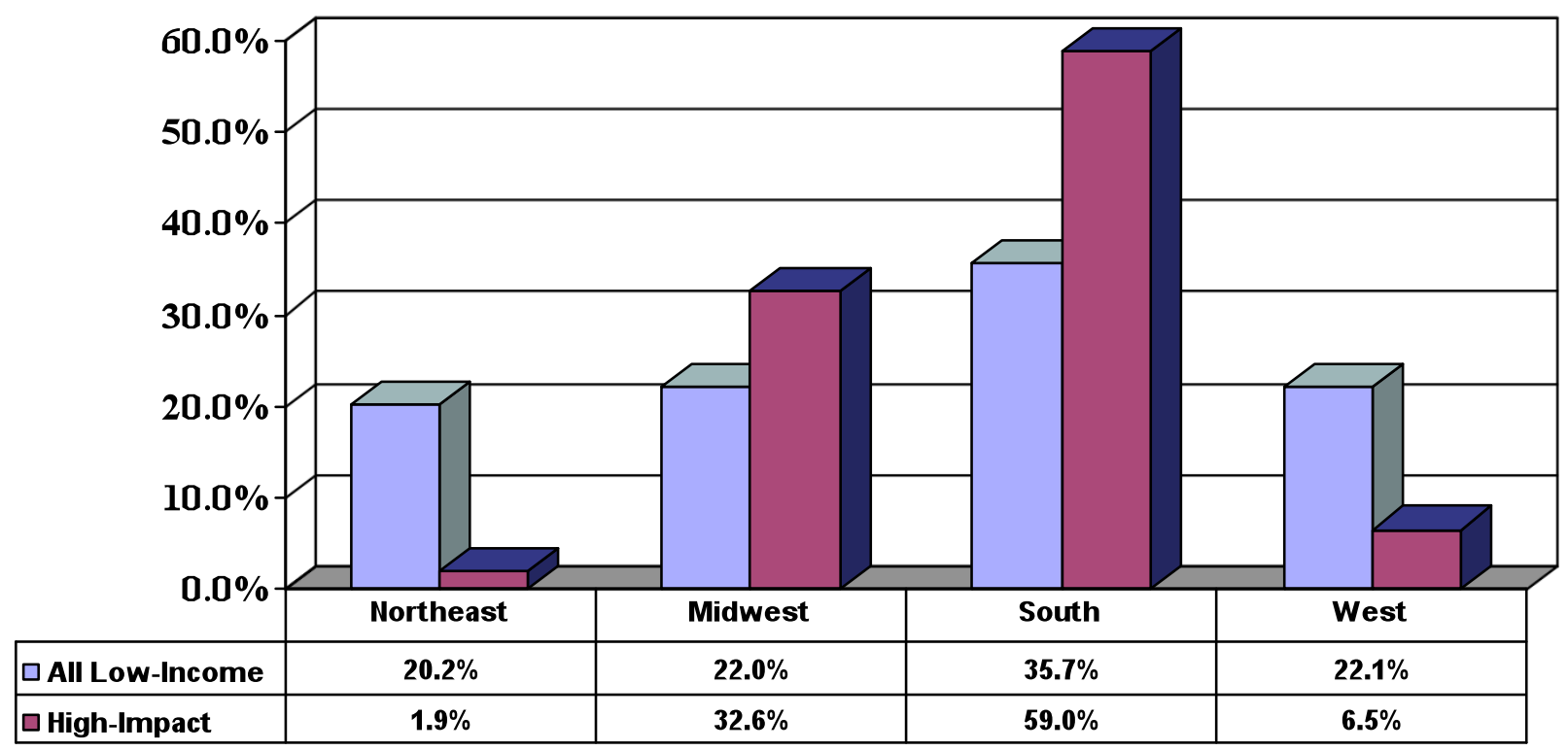

Figure 2. Location of all low-income households and high-impact, low-income households, percentage by region. (Sources: Residential Energy Consumption Survey, 2001, and ORNL analysis of S.280 using EIA price projections.)

- High-impact households have higher electricity consumption, higher total energy consumption, and higher energy usage per square foot of living space when compared to the averages for all low-income households. Average kWh electricity consumption for high-impact households is 16,179 per annum compared to 8,971 for all low-income households. Average total MBtu of energy consumption for these households is 116.3 per annum compared to 86.6 for all low-income households.

- The age of key appliances such as water heaters, refrigerators, and air conditioners does not vary significantly among low-income households in general or those in the highimpact category. There is, however, considerable variation in the type of homes the two groups live in. Eighty-one percent of the high-impact households live in either mobile homes or single-family detached homes. Among the low-income population in general only 54 percent live in these two types of homes.

\section{Household Gasoline Impacts}

- In the business-as-usual case low-income household expenditures for households with vehicles will average $\$ 1829$ per year in 2020 and $\$ 2052$ per year in 2030 . This will increase by $\$ 153$ in 2020 and $\$ 323$ in 2030 under the cap-and-trade scenario.

- Low-income households with personal vehicles had average consumption of 902 gallons per year in 2001 compared to 1231 gallons for non-low-income households. Their 
average expenditures are lower than those of non-low-income households but not in proportion to their lower income. Their personal travel burden, measured as expenditures divided by income, is therefore substantially higher than those of higher income households.

- Their average fuel economy was 20.28 miles per gallon compared to 20.56 for non-lowincome households.

- The impact of cap-and-trade policies on low-income household vehicle expenditures will vary significantly within that population depending on a variety of characteristics including but not limited to vehicle types and numbers owned, geographic location, distances traveled, and ultimately gallons consumed on an annual basis. While the average impact is estimated at $\$ 323$ per year, those in the highest quartile of impact will see an average increase of $\$ 750$ per year. The variation and broad distribution of impacts can be seen in Figure 3.

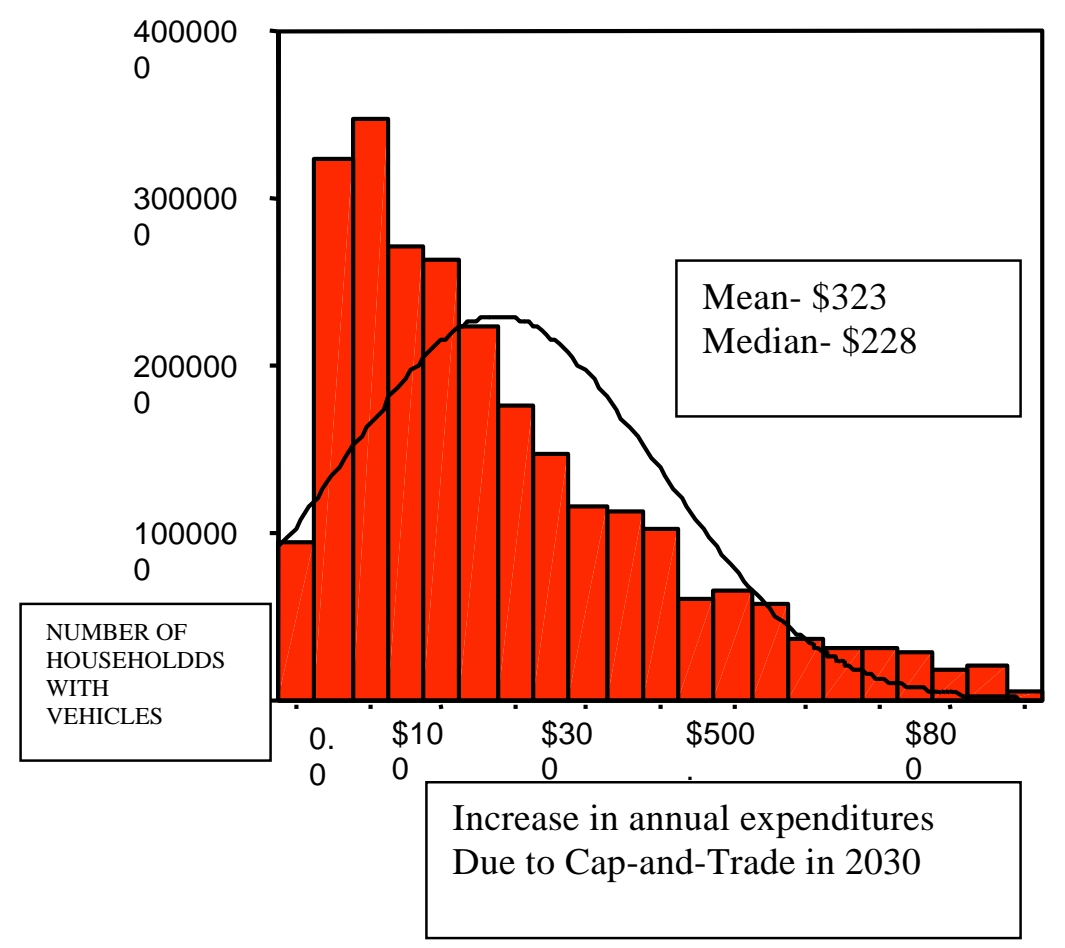

Figure 3. Impact of cap-and-trade on gasoline expenditures for low-income households with vehicles in 2030 .

- A unique characteristic of the variation in impacts is the substantial number of lowincome households, approximately 19 percent, that are estimated to have no vehicle at all. (These do not even appear in Figure 3.) This compares to approximately 3 percent of the non-low-income households. A disproportionate number of these low-income households with no vehicles are located in the Mid-Atlantic Census Division but the majority, 73 percent are found spread across other parts of the country. 


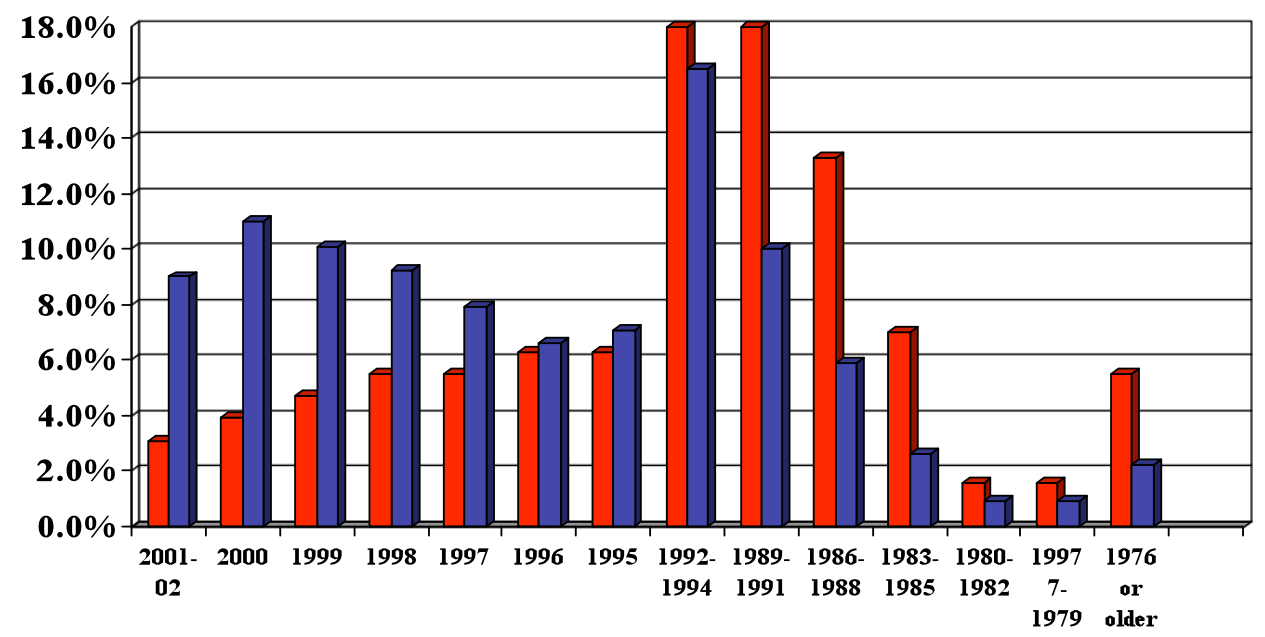

Under $150 \% \square$ Over $150 \%$

POVERTY STATUS OF HOUSEHOLD

Figure 4. Age (model year) of auto fleet by income group, based on 2001 survey data.

- An examination of the survey data reveals that, as one might expect, low-income households are much less likely to own late-model cars. Approximately 47 percent of their vehicles were at least ten years old at the time of the survey. This compares to 23 percent for non-low-income households. In the latter group 39 percent of vehicles were four years old or less, whereas among low-income households that percentage was 17 percent. Please see Figure 4 for details.

- Another clear distinction among low-income households is the difference between households in rural areas and those in non-rural areas. Those in rural areas would experience an average increase of $\$ 424$ per year in 2030, whereas those in non-rural areas would see an average increase of $\$ 291$.

- Geography clearly makes a difference in how far people drive and therefore how much they will have to pay in higher gasoline prices. Those in the Pacific and the Mid-Atlantic Census divisions with vehicles will experience an average increase in their expenditures of \$273 and \$277, respectively. This compares to \$376 for the West South Central Census Division and \$386 in the Mountain Census Division.

\section{CONCLUSIONS}

- This preliminary analysis of one cap-and-trade carbon policy indicates that there will be a substantial impact of such a policy on low-income energy expenditures. This impact will begin at a relatively small level in the years immediately ahead and increase over the 
following decades as the level of carbon dioxide emitted in the U.S. is increasingly constrained.

- The breadth of the impact of a substantial cap-and-trade policy, comparable to the reductions proposed in S.280 and similar proposals, will vary substantially with the program design. The proposal evaluated in this analysis imposes its carbon emissions requirements at the level of large emitters such as power plants and on refineries, and the impact on energy bills for low-income households is therefore largely concentrated in the electricity and gasoline consumption sectors. Other proposals, such as the LiebermanWarner bill, S.2191, seek to impose the allowance requirements on more fuels and at different levels of the production and distribution system and would be more likely to have a high impact on those using natural gas or fuel oil as their primary heat source. In this regard the general design matters.

- Residential and transportation energy expenditures are only part of the regressive impact of a cap-and-trade policy on low-income households because higher energy costs to producers of other essential goods and services are likely to be passed to their customers. Direct energy expenses will, nonetheless, be a significant proportion of the impact of a large-scale carbon pricing policy on low-income households, as the figures above demonstrate.

- These impacts on direct energy expenditures are likely to vary substantially by region, fuel type for electric generation, housing type and condition, primary heating fuel, vehicle age and condition, and numerous other factors. General income redistribution mechanisms such as withholding tax adjustments or the Earned Income Tax Credit may be a major vehicle for helping to deal with the general consumption impacts of the policy and basic energy usage, but may not be well suited to deal with the energy-specific variations explored in this report. This is because those mechanisms are not designed to take these highly varied energy-related benefit requirements into account, nor to deliver energy efficiency services.

- Appropriately funded and designed low-income energy assistance has a significant role to play in dealing with these impact disparities among and within the different regions of the country because the benefits can be varied to target high-impact households.

- The residential energy usage profile of high-impact, low-income households, living disproportionately in detached single family homes and consuming more electricity and more energy in general than other low-income households, indicates that they stand to benefit substantially from energy efficiency investments.

- The gradual introduction of the cap-and-trade carbon restrictions and accompanying price impacts creates a window of opportunity to employ energy efficiency to cushion the future impacts. During the next decade residential building envelope retrofits and appliance replacement, as well as improved auto fleet efficiency targeted at those in the high-impact segment of the low-income population, can help reduce the need for future energy assistance while also reducing the carbon footprint of low-income communities.

- Further analysis of carbon reduction policies with projections of future housing, appliance, and vehicle fleet profiles, as well as various projections of the size, demographics, and economic well-being of the low-income population, will help better assess remedial requirements for these policies as well as better inform targeting for energy assistance and energy efficiency efforts. 


\section{REFERENCES}

Congressional Budget Office, 2003, "Shifting the Cost Burden of a Carbon Cap-and-Trade Program," Washington, D.C.

Eisenberg, J., 2005, "The Impact of Forecasted Energy Price Increases on Low-Income Consumers," Oak Ridge National Laboratory, Oak Ridge, TN.

Energy Information Administration (EIA), National Household Transportation Survey for 2001, Washington, D.C.

EIA, Residential Energy Consumption Survey for 2001, Washington, D.C.

EIA, Office of Integrated Analysis and Forecasting, 2007, Energy Market and Economic Impacts of S.280, the Climate Stewardship and Innovation Act of 2007, Washington, D.C.

Greenstein R., et.al., 2007, "Designing Climate-Change Legislation That Shields LowIncome Households From Increased Poverty and Hardship," Center on Budget and Policy Priorities, Washington, D.C.

Metcalf, G. E., 2007, “A Proposal for a U.S. Carbon Tax Swap,” The Hamilton Project, The Brookings Institution, Washington, D.C.

U.S. Census Bureau, 2006, Income, Poverty, and Health Insurance Coverage In The United States, Washington, D.C.

U.S. Department of Commerce, National Oceanic and Atmospheric Administration, 2007, Historical Climatology Series 5-1, Monthly, State, Regional, and National Heating Degree Days, Asheville, NC.

U.S. Department of Health and Human Services, Administration for Children and Families, 2004-7, LIHEAP Home Energy Notebook, Washington, D.C.

U.S. National Weather Service, Climate Prediction Center, 2007, Experimental Monthly Total Degree Day Forecast, Camp Springs, MD. 


\section{APPENDIX A: METHODOLOGY}

The method used to estimate the impact of projected price increases for residential energy and gasoline on low-income households is based on the integration of three products from the Department of Energy's Energy Information Administration (EIA) — the Residential Energy Consumption Survey (RECS) for 2001, the EIA version of the National Household Transportation Survey (NHTS) for 2001, and EIA's detailed analysis of S.280, Energy Market and Economic Impacts of S.280, the Climate Stewardship and Innovation Act of 2007. RECS is the most recent EIA survey of U.S. households in an occasional series dating back to 1978 that provides detailed data on housing and energy characteristics, demographics, and energy consumption and expenditures verified through billing data. There are records on 4822 individual households in the data base. NHTS public-use files are an EIA product derived from a periodic Department of Transportation Survey containing records for 21,178 households. Detailed information is provided on the number of vehicles per household, vehicle age and model, household location by Census Region and Division, household income and limited demographics, and odometer-based miles traveled per vehicle. Consumption in gallons and related expenditures were derived by EIA from the U.S. Environmental Protection Agency data on model efficiency adjusted for age and real-world driving conditions. The analysis of S.280 provides regional- and division-level electricity and gasoline price projections in 2005 dollars for 2020 and 2030 based on the NEMS model.

The residential projections require the most significant modifications to the underlying RECS data base because of the need to normalize weather conditions and consumption. RECS publicuse files identify the location of each household by Census Region, of which there are four, and by Census Division, of which there are nine. Heating and cooling degree-days are provided for each household for 2001 based on the population-weighted data for each Census Division, and the poverty status of each household is also provided. The survey provides actual fuel bills for each household and uses statistical techniques to allocate the usage and expenditures among major usage categories such as heating, cooling, hot water heating, and refrigeration. Long-range climate normals for heating and cooling degree-days for each of the Census divisions were calculated using statistics provided by the National Climatic Data Center of the National Oceanic and Atmospheric Administration, National Environmental Satellite, Data and Information Service. These data were employed to calculate an adjustment factor for each division so that RECS data on heating and cooling expenditures for 2001 could be adjusted to reflect normalized weather.

Price adjustment factors for electricity were then calculated for the EIA mid-range Business-AsUsual S.280 and cap-and-trade cases for 2020 and 2030.

The estimate of an individual household's electricity expenditure for a given year $\mathrm{n}$ was then calculated using the following formula in SPSS:

$+(($ Dolelsph $*$ hddfact $)+($ Dolelcol $*$ cddfact $)+$ dolelapl+ dolelrfg + dolelwth $) *$ pmel where:

'Dol' signifies the expenditure for 2001,

'el' represents electricity

'hddfact' is the heating degree day adjustment factor for normalization

'cddfact' is the cooling degree day adjustment factor for normalization

'sph' is space heating 
'wth' is water heating

'apl' is appliances

'col' is cooling,

' $\mathrm{rfg}$ ' is refrigerator

'pm' is price multiplier year ' $\mathrm{n}$ '

' $\mathrm{r}$ ' is Census region

' $d$ ' is Census division.

Regional estimates were then made using the sort functions of SPSS to select households by region and qualification of eligibility for LIHEAP and the "Explore" statistical function to derive means, medians, and standard deviations for electricity expenditures by primary heating fuel type for total expenditures, as well as heating and cooling expenditures for each year. Statistics were generated on a weather-normalized basis for 2020 and 2030.

The projections for the impact of the cap-and-trade on gasoline expenditures were calculated using the gallons-per-household data for 2001 in the NHTS database in conjunction with price projections for the Business-As-Usual and Cap-and-Trade scenarios using regional and division gasoline price data for 2020 and 2030 as provided in the EIA analysis of S.280. Households in the low-income population were derived from the survey estimate of income and household size matched against the income bands for households at or below 150 percent of the income poverty level for 2001 as provided by the Poverty Income Guidelines of the Department of Health and Human Services. 


\title{
APPENDIX B: MAP Of CENSUS DIVISIONS AND REGIONS
}

\author{
(Cia) Energy Information Administration
}

$\underline{\text { Home }} \geq$ Regional Energy Profiles $>$ U.S. Census Map

Regional Energy Profiles

U.S. Census Regions and Divisions

Release date: June 14, 2000

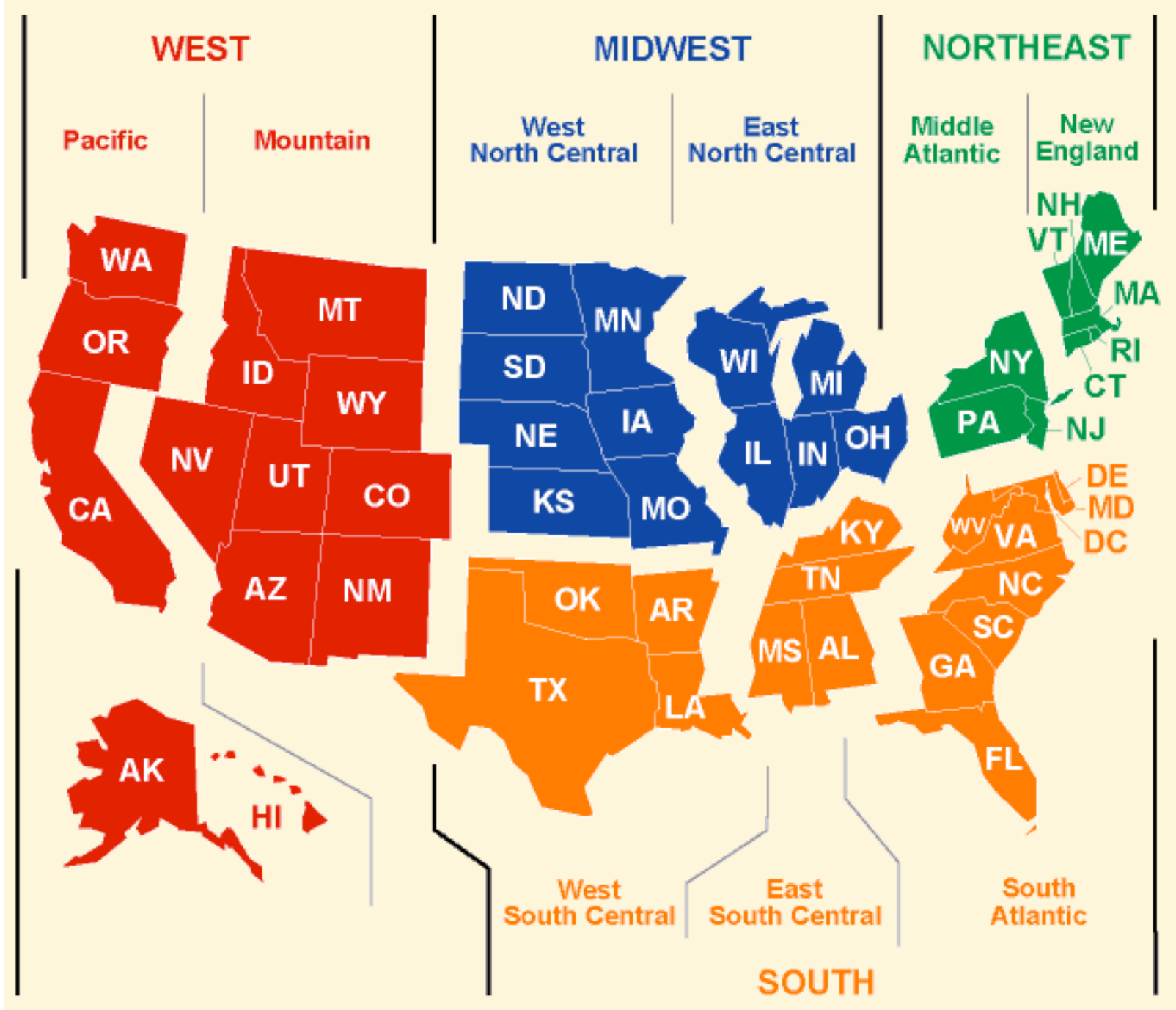

